genetic heterogeneity, will preclude the development of effective vaccines. This possibility is not neglected, but rather shared by everyone developing vaccines against any living pathogen. I fear, however, that Gillett's argument at times oversimplifies the problem. Sex is a very good, but not the only, mode of generating diversity. For viruses, prokaryotes and eukaryotes alike, genetic variation as a result of acquiring foreign DNA is relatively common. For example, each year epidemics with antibiotic-resistant bacteria result from transmission of genetic material between different species.

Many parasites have sexual and asexual stages of reproduction, and at times the heterogeneity as well as the selective pressure can be found during the asexual stages. Selection for drug resistance and antigenic variation occurs in the asexual blood stages of Plasmodium species. The genome of Plasmodium is known to be remarkably flexible in the asexual siages ${ }^{2}$ so that genetic variation need not be the result of sexual recombination. Further, it is not clear that trypanosomes have a sexual stage, yet a single asexual individual is equipped to present more than 1,000 variants. For most important bacterial and viral pathogens no vaccine exists despite the absence of sexual reproduction in these organisms.

The existence of a sexual stage in itself does not make vaccine development any more difficult. Sexual reproduction in a parasite does not necessarily result in an impossible array of antigenic types. Theoretical considerations aside, no ${ }^{3}$ or few $^{4}$ antigenic differences are noted between geographically isolated strains of Schistosoma mansoni. Because most helminths do not multiply within the definitive host, they present a different kind of problem for host defence mechanisms than either prokaryotes or protozoa. Limited antigenic variation has not been an obstacle to the development of successful vaccines against polio, influenza virus, meningococcus and the pneumococcus.

The absence of sexual reproduction does not guarantee success in vaccine development, similarly, its presence does not guarantee failure. It is clear that

\title{
New cuprate superconductors
}

SIR-In the high-temperature supercon- cium by strontium is necessary to obtain ductors $\mathrm{Bi}_{2} \mathrm{Sr}_{2} \mathrm{Ca}_{n-1} \mathrm{Cu}_{n} \mathrm{O}_{2 n+4}$ and $\mathrm{Tl}_{2} \mathrm{Ba}_{2}-$ $\mathrm{Ca}_{n-1} \mathrm{Cu}_{n} \mathrm{O}_{2 n+4}$ (ref. 1), the basic structural units are layers of $\mathrm{Ca}(\mathrm{Sr}) \mathrm{CuO}_{2}$ and the $n=1$ compound. For example, the combination of one $\mathrm{CaCuO}_{2}$ layer with $\mathrm{Bi}_{2} \mathrm{Sr}_{2}$ $\mathrm{CuO}_{6}(n=1)$ makes $\mathrm{Bi}_{2} \mathrm{Sr}_{2} \mathrm{CaCu}_{2} \mathrm{O}_{8}$ $(n=2)$, two layers of $\mathrm{CaCuO}_{2}$ make $\mathrm{Bi}_{2} \mathrm{Sr}_{2} \mathrm{Ca}_{2} \mathrm{Cu}_{3} \mathrm{O}_{10}(n=3)$, aand $(n-1)$ layers gives $\mathrm{Bi}_{2} \mathrm{Sr}_{2} \mathrm{Ca}_{n-1} \mathrm{Cu}_{n}$ $\mathrm{O}_{2 n++}$. For this reason, $\mathrm{Ca}(\mathrm{Sr})^{n}$ $\mathrm{CuO}_{2}$ has been called "the parent structure of high-temperature superconductors" $"$. We have put this concept into action by depositing layers of $\mathrm{Ca}(\mathrm{Sr}) \mathrm{CuO}_{2}$ of desired $n$ on a substrate and periodically inserting a layer of $\mathrm{Bi}_{2} \mathrm{Sr}_{2}$ $\mathrm{CuO}_{6}$. We do this using the technique of laser molecular-beam epitaxy $^{3.4}$, and we have succeeded in synthesizing thin films not only of $\mathrm{Bi}_{2} \mathrm{Sr}_{2} \mathrm{Ca}_{n-1} \mathrm{Cu}_{n} \mathrm{O}_{2 n+4}$ with $n=1-5$, which have already been reported $^{3}$, but also of the $n=6,7$ and 8 compounds.
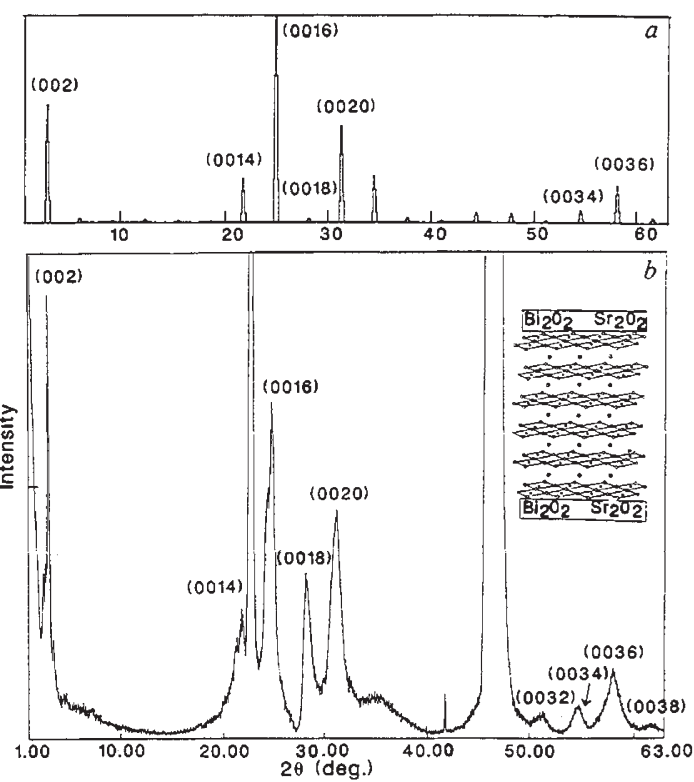

X-ray diffraction pattern of the $\mathrm{Bi}_{2} \mathrm{Sr}_{2} \mathrm{Ca}_{n-1} \mathrm{Cu}_{n} \mathrm{O}_{2 n+4}$ film

In the experiment we report with $n=6$. The calculated pattern (a) based on the struchere, two targets, $\mathrm{Ca}_{10.88} \mathrm{Sr}_{0.1 .1} \mathrm{CuO}_{2}$ ture in the inset $\left(\mathrm{Bi}_{2} \mathrm{Sr}_{2} \mathrm{Ca}_{5} \mathrm{Cu}_{6} \mathrm{O}_{16}\right)$ coincides with the and $\mathrm{Bi}_{2} \mathrm{Sr}_{2} \mathrm{CuO}_{6}$, are alternately observed $\mathrm{X}$-ray diffraction pattern $(b)$.

ablated by a pulsed ArF excimer laser with peaks at $2 \theta=27.5^{\circ}(001)$ and $58.4^{\circ}(002)$.) appropriate duration, and the layers are deposited on a $\mathrm{SrTiO}_{3}(100)$ substrate at $500-630^{\circ} \mathrm{C}$ in oxygen gas at a pressure of $6 \times 10^{-3}$ torr.

The first step in the synthesis of any member of the $\mathrm{Bi}_{2} \mathrm{Sr}_{2} \mathrm{Ca}_{n-1} \mathrm{Cu}_{n} \mathrm{O}_{2 n+4}$ family is to deposit layers of $\mathrm{Ca}(\mathrm{Sr}) \mathrm{CuO}_{2}$ with the $c$ axis perpendicular to the substrate surface. The partial substitution of cal-

The next step is the insertion of $\mathrm{Bi}_{2} \mathrm{Sr}_{2}$ $\mathrm{CuO}_{\hbar}$ layers as required, to produce the different $n$ values of $\mathrm{Bi}_{2} \mathrm{Sr}_{2} \mathrm{Ca}_{n-1} \mathrm{Cu}_{n} \mathrm{O}_{2 n++}$. The number of $\mathrm{Ca}(\mathrm{Sr}) \mathrm{CuO}_{2}$ layers sandwiched by $\mathrm{Bi}_{2} \mathrm{Sr}_{2} \mathrm{CuO}_{6}$ layers can be controlled by $a$ thickness monitor ${ }^{5}$ and confirmed by the oscillation in intensity of reflection high-energy electron diffraction peaks. Large- $n$ compounds are formed development of vaccines against parasites will not be easy, however: their means of reproduction may not present the main obstacle so much as their complexity. The ability of parasites to present complex surfaces, to repair damage and to otherwise tolerate noxious attacks by their host may be the truly limiting factor. Therefore, the merits and demerits of vaccine strategies compared to other methods of control must be weighed for each pathogen and should not be based on a single aspect of their biology.

\section{Division of Geographic Medicine}

Department of Medicine,

Case Western Reserve University School of Medicine,

2109 Adelbert Road,

Cleveland, Ohio 44106, USA

1. Gillett, J.D. Nature 348, 494 (1990).

2. Weber, J.A. Expl Parasit. 66, 143-170 (1988).

3. Smithers, S.R., Clegg, J.A. \& Snary, D. Trans. R. Soc. trop. Med. Hyg. 78, 187-189 (1984).

4. Blanton, R., Horowitz, S., Dos Reis, M.G., Rottman, F. \& Mahmoud, A.A.F. J. Parasit. 72, 445-453 (1985).

simply by increasing the number of $\mathrm{Ca}(\mathrm{Sr}) \mathrm{CuO}_{2}$ layers sandwiched by the $\mathrm{Bi}_{2} \mathrm{Sr}_{2} \mathrm{CuO}_{6}$ layer. The X-ray diffraction pattern of the newly formed $\mathrm{Bi}_{2} \mathrm{Sr}_{2}$ $\mathrm{Ca}_{5} \mathrm{Cu}_{6} \mathrm{O}_{16}(n=6)$ compound is shown in the figure. Not only the position of the (002) peak at $2 \theta=3.0^{\circ}$ but also the total $\mathrm{X}$-ray pattern coincides with that calculated for the $n=6$ compound ( $c=58.8 \AA$ ). In a similar manner, the $n=7$ and $8 \mathrm{com}$ pounds can be formed by this technique.

We believe that the inability, until now, to synthesize the $n=6-8$ compounds has been due to insufficient care in growing the $\mathrm{Ca}(\mathrm{Sr}) \mathrm{CuO}_{2}$ parent material. This basic concept and the synthesis technique described here should be useful in the design and creation of other new layered compounds.

\section{TOMOJ KAWAI YOSIHIRO EGAMI HITOSHI TABATA SHICHIO KaWAI \\ Institute of Scientific and Industrial Research, \\ Osaka University, \\ Mihogaoka, Ibaraki 567, Japan \\ 1. Torardi, C.C. et al. Science 240, 632-633 (1988). \\ 2. Siegrist, T., Zahurak, S.M., Murphy, D.W. \& Roth, R.S. Nature 334, 231-232 (1988) \\ 3. Kanai, M., Kawai, T. \& Kawai, S. Appl. Phys. Lett. 54, $1802-1804$ (1989) \\ 4. Tabata, H., Murata, O., Kawai, T. \& Kawai, S. Appl. Phys. Lett. 56, 1576-1578 (1990). \\ 5. Kanai, M., Kawai, T. \& Kawai, S. Appl. Phys. Lett. 57, $198-200$ (1990)}

\section{Correction}

IN the Scientific Correspondence from Kennedy et al. 'Striate cortex periodicity' (Nature 348, 494; 1990) reference 5 should have read: (C. Dehay, G. Horsburgh, M. Berland, H. Killackey and $\mathrm{H}$. Kennedy, manuscript in preparation). 